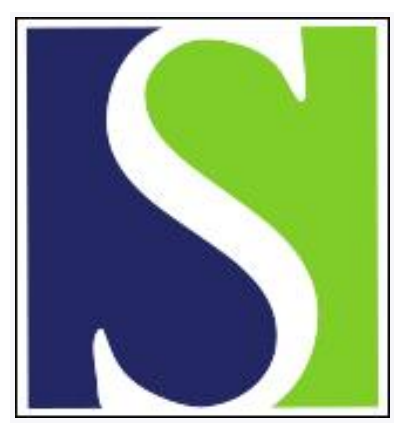

Scand J Work Environ Health 1986;12(4):365-370

https://doi.org/10.5271/sjweh.2127

Issue date: Aug 1986

Association between vibration-induced white finger and hearing loss in forestry workers.

by Iki M, Kurumatani N, Hirata K, Moriyama T, Satoh M, Arai T

This article in PubMed: www.ncbi.nlm.nih.gov/pubmed/3775325

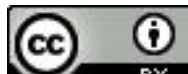




\title{
Association between vibration-induced white finger and hearing loss in forestry workers
}

by Masayuki Iki, MD, PhD, ${ }^{1,2}$ Norio Kurumatani, MD, PhD, ${ }^{1}$ Kuniaki Hirata, MD, ${ }^{1}$ Tadashige Moriyama, MD, PhD, ${ }^{1}$ Masashi Satoh, MD, ${ }^{3}$ Takakazu Arai, $\mathrm{MD}^{3}$

\begin{abstract}
IKI M, KURUMATANI N, HIRATA K, MORIYAMA T, SATOH M, ARAI T. Association between vibration-induced white finger and hearing loss in forestry workers. Scand J Work Environ Health 12 (1986) $365-370$. The present investigation was a case-referent study in which age and hours of vibrating tool operation were matched for the cases and referents in an effort to confirm the earlier reported difference in hearing loss between workers with vibration-induced white finger (VWF) and those without VWF. Thirty-seven pairs were formed from 51 men with VWF and 228 without it. The greatest hearing loss was at $4 \mathrm{kHz}$ in both the case and reference groups, as is usually found in typical noise-induced hearing loss. The case group had a higher hearing threshold than the reference group at every frequency, and the difference was significant at 4 and $8 \mathrm{kHz}$ and almost so at $2 \mathrm{kHz}$. As corroboration for this association, the subjects were divided into three groups by recovery rate of skin temperature 5 min after cold provocation at $10^{\circ} \mathrm{C}$ for $10 \mathrm{~min}$, a procedure which is one of the valid objective tests for VWF. The subjects with the most delayed recovery reached the highest age-corrected median hearing level at $4 \mathrm{kHz}$, and those with the promptest recovery marked the lowest. The cause of this increased damage of hearing in relation to VWF is not known. However, the association between VWF and hearing loss is interesting in view of the effects of vibration on parts of the body other than the hand and arm.
\end{abstract}

Key terms: effect of vibration on cochlea, etiology of noise-induced hearing loss, fingertip skin temperature, matched-pair analysis, peripheral circulatory disturbance, Raynaud's phenomenon, sympathetic nervous system.

Forestry workers using chain saws run the risk of both vibration syndrome (18) and noise-induced hearing loss $(7,9)$. Recently Pyykkö et al $(17)$ reported that lumberjacks with a history of vibration-induced white finger (VWF) had a hearing loss at $4 \mathrm{kHz}$ that was about $10 \mathrm{~dB}$ greater than that of lumberjacks without a history of VWF. They suggested that the extra hearing loss was based on sympathetic vasoconstriction induced by local vibration not only in the fingers but also in the inner ear. This proposal is interesting in view of effects of local vibration on parts of the body other than the hand and arm. However, before an association between VWF and hearing loss can be established, possible confounding by age and exposure to noise have to be simultaneously eliminated. Therefore, we have done a matched-pair case-referent study designed to allow for such confounding (10).

Rewarming features of fingertip skin temperature after cold provocation of the hand are known to represent the digital circulatory functions well and are

\footnotetext{
1 Department of Public Health, Nara Medical University, 840 Shijo-cho, Kashihara City, Nara 634, Japan.

2 Present address: Department of Hygiene and Public Health, Osaka Medical College, 2-7 Daigaku-machi, Takatsuki City, Osaka 569, Japan.

3 Kiwa Hospital, 1103 Konono, Hashimoto City, Wakayama 648, Japan.
}

Reprint requests to: Dr M Jki, Department of Hygiene and Public Health, Osaka Medical College, 2-7 Daigaku-machi, Takatsuki City, Osaka 569, Japan widely used as an objective test for VWF in Japan (4, 13). To confirm the association between VWF and hearing loss, we have assessed whether or not the hearing of workers with peripheral circulatory disturbance was more severely affected by noise than that of healthy men.

\section{Subjects and methods}

Among 543 forestry workers (524 males and 19 females) who voluntarily underwent the annual medical examination for vibration syndrome in 1980, 360 men were selected as the subjects for the analyses. They had no history of ear disease, vertigo, head injury, or the intake of drugs liable to affect hearing. Conductive deafness was eliminated as a diagnosis on the basis of otoscopy and audiometry. Among the 360 men examined, 289 had no history of occupational noise exposure other than that of chain saws, bush cleaners, or winches, and their total operating hours for all the tools were evaluated.

In the audiometric examination pure-tone air-and bone-conduction hearing level was measured at frequencies of $0.5,1,2,4$, and $8 \mathrm{kHz}$ in 5 -dB steps with a diagnostic audiometer (Rion AA-62), which was calibrated according to Japanese industrial standard JIS T 1201-1963 (12). Audiometry was conducted in a portable soundproof chamber (Rion AT-4C) located in a quiet room, where the background noise level was always lower than $40 \mathrm{~dB}(\mathrm{~A})$. Each subject was free 


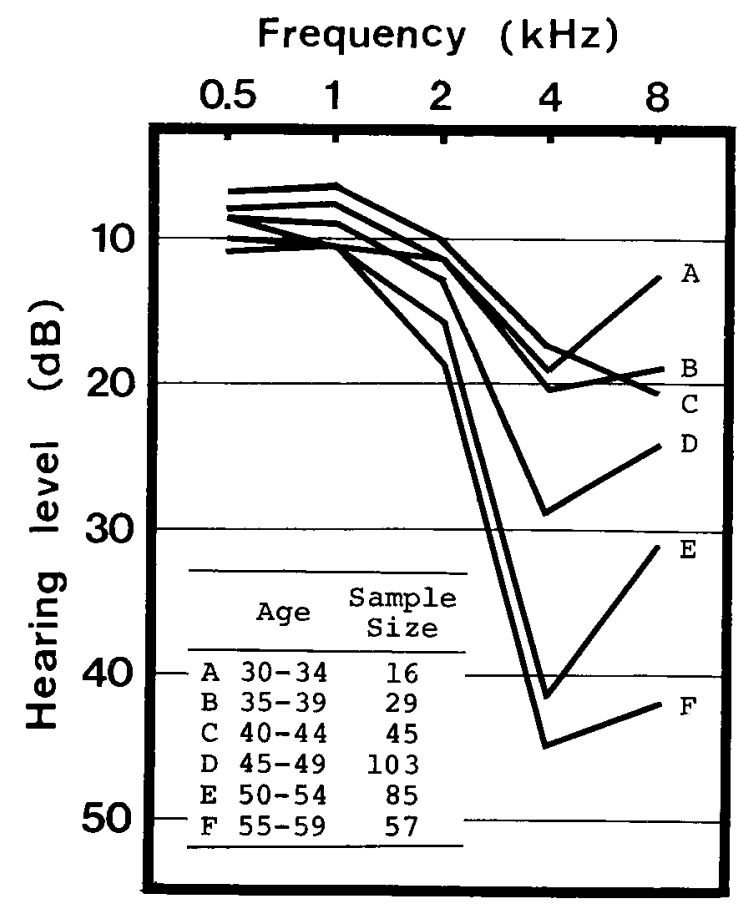

Figure 1. Median values of the audiograms of the five-year age groups of the subjects.

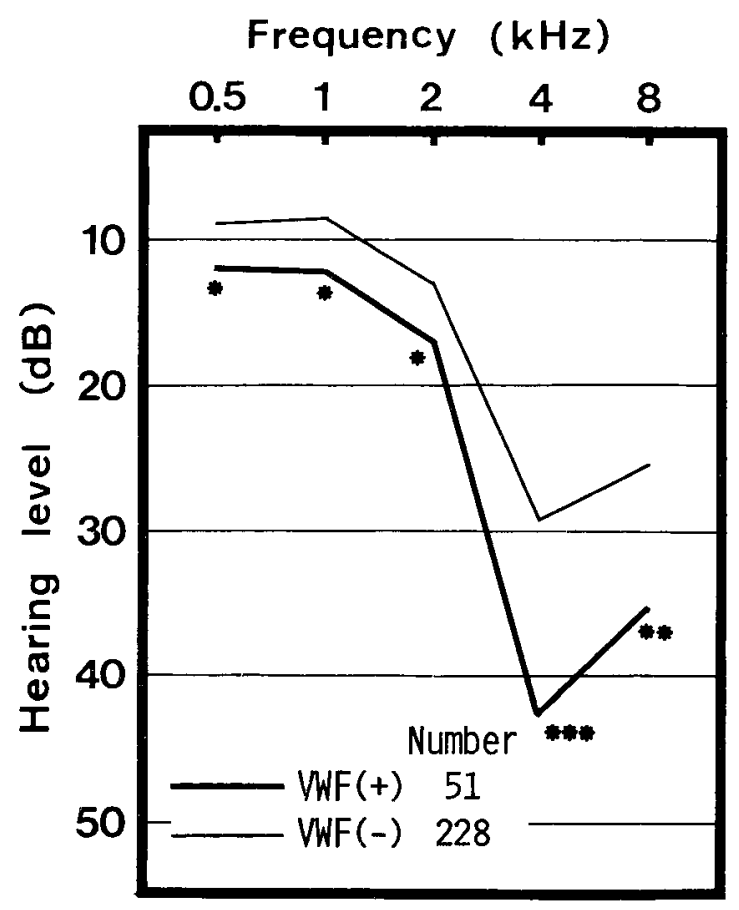

Figure 2. Median values of the audiograms of the subjects with [VWF(+)] and without [VWF $(-)]$ vibration-induced white finger (VWF). $\left(" p<0.05,{ }^{* \star} p<0.01,{ }^{* \star *} p<0.001\right.$, one-tailed Mann-Whitney test).
Table 1. Mean age of the subjects and the mean number of operating hours for the vibrating tools used.

\begin{tabular}{|c|c|c|}
\hline & Mean & SD \\
\hline \multicolumn{3}{|l|}{ All the subjects $(N=360)$} \\
\hline Age (years) & 48.1 & 8.2 \\
\hline \multicolumn{3}{|l|}{$\begin{array}{l}\text { Subjects whose hours of tool use } \\
\text { were known }(N=289)\end{array}$} \\
\hline Age & 48.0 & 8.2 \\
\hline \multicolumn{3}{|l|}{ Operating hours } \\
\hline Chain saws $\left(\mathbf{N}=281^{\text {a }}\right)$ & 4762 & 4613 \\
\hline Bush cleaners $\left(N=124^{a}\right)$ & 3531 & 4478 \\
\hline Winches $\left(\mathrm{N}=112^{\mathrm{a}}\right)$ & 7518 & 8162 \\
\hline
\end{tabular}

a Number of workers who had operated the tool.

from the noise of the tools for at least $18 \mathrm{~h}$ prior to the audiometric examination.

The hand suffering from VWF or numbness or the right hand in the case of subjects without symptoms was immersed to the wrist in water at $10 \pm 0.5^{\circ} \mathrm{C}$ for $10 \mathrm{~min}$. The skin temperature of the third fingertip of the immersed hand was measured with a digital thermistor thermometer (Takara HD-111) before and at the end of the immersion, and then 5 and $10 \mathrm{~min}$ after the immersion. The room temperature was kept at $20-23{ }^{\circ} \mathrm{C}$ throughout the measurements.

The recovery rate of the fingertip skin temperature $\mathrm{X}$ minutes after the immersion $\left(\mathrm{RR}_{\mathrm{x}}\right)$ was calculated as follows:

$$
R R_{x}=\left(T_{x}-T_{\text {end }}\right) /\left(T_{\text {before }}-T_{\text {end }}\right),
$$

where $T_{\text {before }}, T_{\text {end }}$, and $T_{x}=$ fingertip skin temperatures before, at the end of, and $\mathrm{X}$ minutes after the immersion, respectively.

Operating years, mean operating hours per year, and mean operating hours per day for chain saws, bush cleaners, and winches up to the test date were obtained in the detailed interviews. Total hours of work with each tool were calculated by multiplying these three parameters.

A diagnosis of VWF was formed when one of the authors judged a subject to have had a typical history of blanching of the digits in the detailed interviews.

Of the 289 men with no occupational noise exposure other than that of the tools in question, 51 (17.6 \%) had had VWF [VWF (+) group], and $228(78.9 \%)$ had not [VWF( - ) group]; the other $10(3.5 \%)$ were those who had had a suspicious attack. Thirty-seven case-referent pairs matched for age and exposure duration could be formed from the $\operatorname{VWF}(+)$ and VWF $(-)$ groups. The referents were matched to the same five-year age group as the cases, and their operating hours for each tool were almost equal to or larger in some degree than those of the cases.

Hearing losses according to the Japanese standard (JIS T 1201-1963) were converted to those on the basis of the international standard (11). The airconduction hearing level of the left ear was analyzed. The difference of the median hearing levels was test- 
Table 2. Age of the workers with and without vibration-induced white finger (VWF) and their hours of work with the vibrating tools. (NS = not significant)

\begin{tabular}{|c|c|c|c|c|c|c|c|c|c|}
\hline \multirow{3}{*}{ Group ${ }^{a}$} & \multirow{3}{*}{$\begin{array}{c}\text { Sample } \\
\text { size }\end{array}$} & \multirow{2}{*}{\multicolumn{2}{|c|}{$\begin{array}{c}\text { Age } \\
\text { (years) }\end{array}$}} & \multicolumn{6}{|c|}{ Hours of work } \\
\hline & & & & \multicolumn{2}{|c|}{ Chain saws } & \multicolumn{2}{|c|}{ Bush cleaners } & \multicolumn{2}{|c|}{ Winches } \\
\hline & & Mean & SD & Mean & SD & Mean & SD & Mean & SD \\
\hline $\begin{array}{l}\text { VWF }(+) \\
\text { VWF(-) }\end{array}$ & $\begin{array}{r}51 \\
228\end{array}$ & $\begin{array}{l}51.2 \\
47.1\end{array}$ & $\begin{array}{l}6.7 \\
8.5\end{array}$ & $\begin{array}{l}7929 \\
3898\end{array}$ & $\begin{array}{l}6360 \\
3833\end{array}$ & $\begin{array}{l}1074 \\
1644\end{array}$ & $\begin{array}{l}2292 \\
3656\end{array}$ & $\begin{array}{l}4713 \\
2614\end{array}$ & $\begin{array}{l}8916 \\
5570\end{array}$ \\
\hline t-test & & \multicolumn{2}{|c|}{$p<0.01$} & \multicolumn{2}{|c|}{$p<0.01$} & \multicolumn{2}{|c|}{ NS } & \multicolumn{2}{|c|}{ NS } \\
\hline
\end{tabular}

a $\operatorname{VWF}(+)=$ subjects with VWF among the 289 workers with exposure history evaluated, $\mathrm{VWF}(-)=$ subjects with no history of VWF.

Table 3. Age of the cases and referents and their hours of work with the vibrating tools.

\begin{tabular}{|c|c|c|c|c|c|c|c|c|c|}
\hline \multirow{3}{*}{ Group } & \multirow{3}{*}{$\begin{array}{l}\text { Sample } \\
\text { size }\end{array}$} & \multirow{2}{*}{\multicolumn{2}{|c|}{$\begin{array}{c}\text { Age } \\
\text { (years) }\end{array}$}} & \multicolumn{6}{|c|}{ Hours of work } \\
\hline & & & & \multicolumn{2}{|c|}{ Chain saws } & \multicolumn{2}{|c|}{ Bush cleaners } & \multicolumn{2}{|c|}{ Winches } \\
\hline & & Mean & SD & Mean & $S D$ & Mean & SD & Mean & SD \\
\hline $\begin{array}{l}\text { Cases } \\
\text { Referents }\end{array}$ & $\begin{array}{l}37 \\
37\end{array}$ & $\begin{array}{l}49.9 \\
50.1\end{array}$ & $\begin{array}{l}5.8 \\
6.2\end{array}$ & $\begin{array}{l}6057 \\
6052\end{array}$ & $\begin{array}{l}3475 \\
3455\end{array}$ & $\begin{array}{r}1193 \\
843\end{array}$ & $\begin{array}{l}2389 \\
1667\end{array}$ & $\begin{array}{l}3063 \\
4633\end{array}$ & $\begin{array}{l}5723 \\
7323\end{array}$ \\
\hline t-test ${ }^{a}$ & & \multicolumn{2}{|c|}{ NS } & \multicolumn{2}{|c|}{ NS } & \multicolumn{2}{|c|}{ NS } & \multicolumn{2}{|c|}{$p<0.05$} \\
\hline
\end{tabular}

a Two-tailed Student's t-test for paired samples.

ed by the one-tailed Wilcoxon's paired rank test for paired samples and the one-tailed Mann-Whitney test for unpaired samples.

\section{Results}

\section{General features of the subjects}

Table 1 shows the mean age of the subjects and the hours of work with the three types of tools used by the subjects. Among the 289 subjects whose exposure history was being evaluated, 60 men had worked only with chain saws and 8 only with bush cleaners. The rest had used two or three different types of tools.

Figure 1 represents the median values of the audiograms of the five-year age groups of 335 subjects. Twenty-five men who were younger than 30 years of age or older than 60 were excluded. The older the subjects, the higher the hearing levels, especially at 4 and $8 \mathrm{kHz}$. The greatest hearing loss, however, was observed at $4 \mathrm{kHz}$ in most of the groups, and this type of audiogram is typical of noise-induced hearing loss. The hearing levels at $4 \mathrm{kHz}$ of all the age groups were significantly higher than those of the same-aged normal Japanese population with no exposure to noise (20). Therefore, the hearing of the subjects was affected by noise, as well as by ageing.

\section{Vibration-induced white finger and hearing loss}

Figure 2 illustrates the median audiograms of the $\mathrm{VWF}(+)$ and $\mathrm{VWF}(-)$ groups. The greatest hearing loss was at $4 \mathrm{kHz}$ in both groups. The VWF $(+)$ group had a significantly higher hearing threshold at every frequency than the $\mathrm{VWF}(-)$ group. The comparison of age and hours of exposure to noise between these two groups is represented in table 2 . The subjects of the VWF $(+)$ group were significantly older and had used chain saws for more hours than those of the VWF (-) group. Therefore it could not be determined which of these features (age, operating hours, or VWF) was related to the difference in hearing level.

Table 3 shows the mean age and operating hours for the three tools of the cases and referents. The two groups were closely matched for age and hours of work with chain saws. The cases, however, had worked significantly fewer hours with winches than had their reference pairs. On the other hand, they had used bush cleaners for rather more hours than the referents so that the total hours of work with the three tools were considered to be adequately matched for the pairs.

Figure 3 illustrates the median audiograms of the cases and referents. The cases had a greater median hearing loss than the referents at every frequency. These differences were not so large as shown in the comparison between the $\operatorname{VWF}(+)$ and $\operatorname{VWF}(-)$ groups (figure 2) since the effects of age and exposure to noise had been eliminated in this analysis. However, the difference remained significant at 4 and $8 \mathrm{kHz}$ $(p<0.05)$ and almost so at $2 \mathrm{kHz}(\mathrm{p}=0.06)$.

\section{Fingertip skin temperature and hearing loss}

The subjects whose ages ranged between 45 and 59 years and whose total hours of work with all the tools were less than $8000 \mathrm{~h}$ were divided into three groups according to the recovery rate of their fingertip skin temperature $5 \mathrm{~min}$ after cold provocation. Group 1 had the highest recovery rate, and group 3 had 


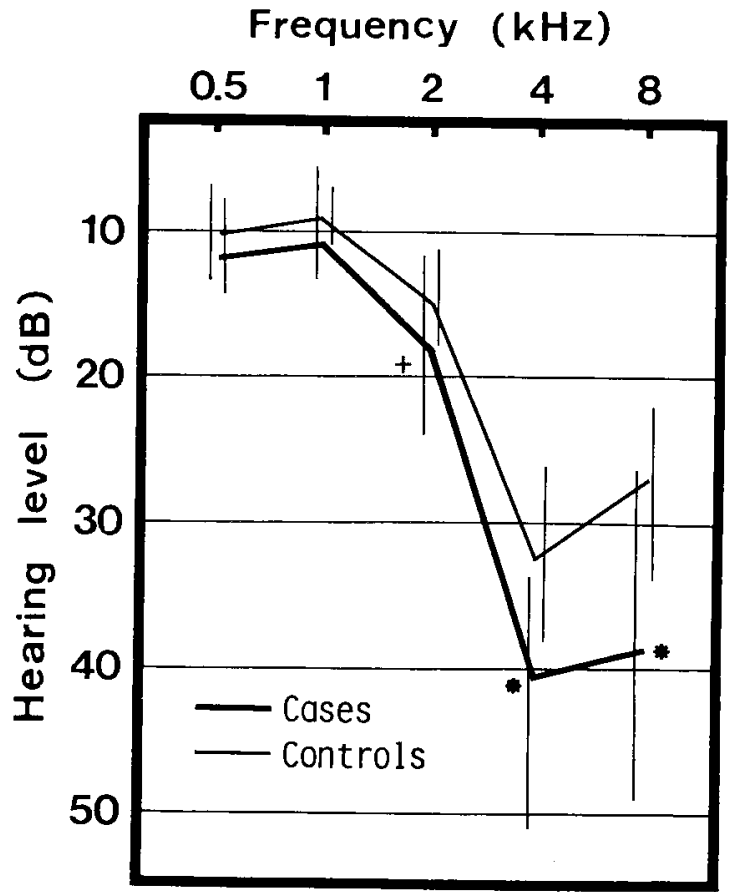

Figure 3. Median values of the audiograms of the case and reference (control) groups. The cases and referents were matched for age and hours of tool operation from the group with and that without vibration-induced white finger. The vertical bars represent the $95 \%$ confidence limits of the medians ( ${ }^{*} p<0.05,+p=0.06$, one-tailed Wilcoxon's paired rank test).

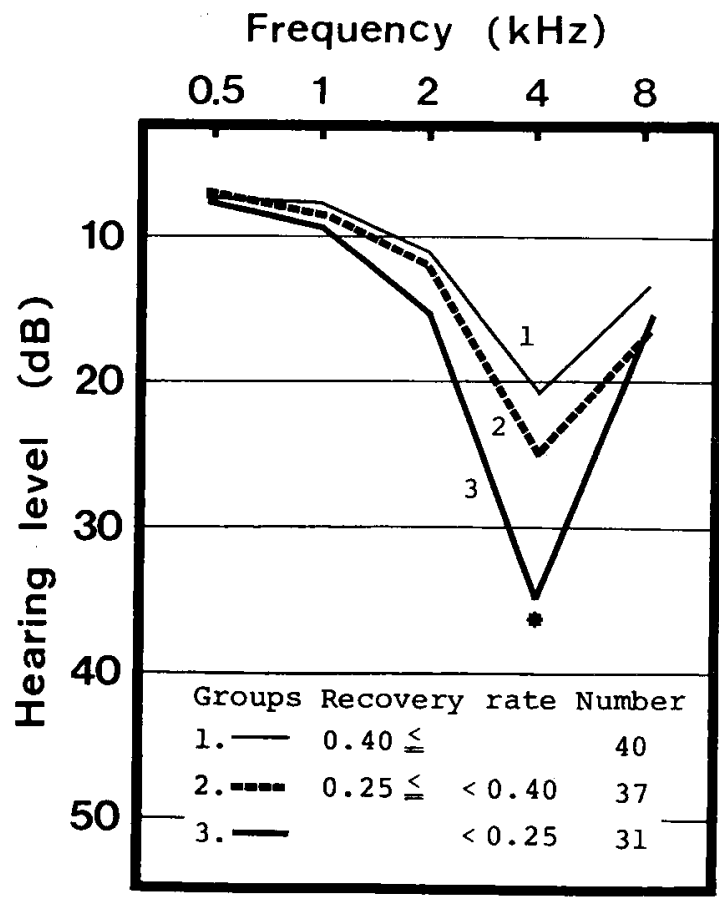

Figure 4. Age-corrected median values of the audiograms of the groups formed on the basis of the recovery rate of the fingertip skin temperature 5 min after cold provocation ${ }^{\star} p<0.05$ versus group 1, one-tailed Mann-Whitney test). The subjects were limited to the men whose age ranged between 45 and 59 years and whose number of workhours with all the tools was $<8000$. See the Subjects and Methods section for the calculation of the recovery rate $(1=$ group with recovery rate of $\geq$ $0.40,2=$ group with recovery rate of $0.25-0.39,3=$ group with recovery rate of $<0.25$ ).

Table 4. Age of the groups divided by recovery rate of fingertip skin temperature 5 min after cold provocation at $10^{\circ} \mathrm{C}$ for $10 \mathrm{~min}$ and their hours of work with the vibrating tools.

\begin{tabular}{|c|c|c|c|c|c|c|c|c|c|c|}
\hline \multirow{3}{*}{ Group ${ }^{a}$} & \multirow{3}{*}{$\begin{array}{l}\text { Recovery } \\
\text { rate }^{\mathrm{b}}\end{array}$} & \multirow{3}{*}{$\begin{array}{l}\text { Sample } \\
\text { size }\end{array}$} & \multirow{2}{*}{\multicolumn{2}{|c|}{$\begin{array}{c}\text { Age } \\
\text { (years) }\end{array}$}} & \multicolumn{6}{|c|}{ Hours of work } \\
\hline & & & & & \multicolumn{2}{|c|}{ Chain saws } & \multicolumn{2}{|c|}{ Bush cleaners } & \multicolumn{2}{|c|}{ Winches } \\
\hline & & & Mean & SD & Mean & SD & Mean & SD & Mean & SD \\
\hline $\begin{array}{l}1 \\
2 \\
3 \\
\end{array}$ & $\begin{array}{c}\geq 0.40 \\
0.25-0.39 \\
<0.25\end{array}$ & $\begin{array}{l}40 \\
37 \\
31\end{array}$ & $\begin{array}{l}50.2 \\
51.5 \\
52.6^{*}\end{array}$ & $\begin{array}{l}3.9 \\
4.0 \\
3.6\end{array}$ & $\begin{array}{l}2810 \\
2358 \\
3067\end{array}$ & $\begin{array}{l}2122 \\
1767 \\
2199\end{array}$ & $\begin{array}{l}559 \\
861 \\
598\end{array}$ & $\begin{array}{l}1375 \\
1523 \\
1053\end{array}$ & $\begin{array}{l}271 \\
461 \\
377\end{array}$ & $\begin{array}{r}889 \\
1192 \\
1098\end{array}$ \\
\hline
\end{tabular}

a The subjects were limited to the men whose age ranged between 45 and 59 years and whose total number of hours of work with all the tools was $<8000$.

b See the Subjects and Methods section for the calculation of the recovery rate.

* $\mathrm{p}<0.01$, versus value of group 1 , two-tailed Student's t-test.

the lowest. Table 4 shows the mean age and operating hours of the three tools for each group. No significant difference was found in operating hours for the tools between any two of the groups. However, the difference between the mean ages of groups 1 and 3 was statistically significant. To eliminate the effect of this age difference, an age correction for hearing level was applied to the subjects. The age-corrected hearing level was obtained by subtracting the median hearing loss, as a function of age of normal Japanese ears not exposed to noise (20), from the recorded level of the subjects.
The workers whose total operating hours for all the tools exceeded $8000 \mathrm{~h}$ were eliminated in this study because we could not match the workhours with each type of tool between the groups divided by the recovery rate.

Figure 4 shows the age-corrected median audiograms of the groups. Group 3 had the highest hearing levels, and group 1 the lowest at 1,2 , and $4 \mathrm{kHz}$. The difference in the hearing level at $4 \mathrm{kHz}$ was significant $(p<0.05)$ between groups 1 and 3. Similar results were obtained when the skin temperature at the end of or 
5 min after the cold provocation was used as a parameter of digital circulatory function.

\section{Discussion}

It has been accepted that vibration syndrome is comprised of VWF, numbness in the hands or arms, excessive muscle fatigue, and bone and joint injuries (19). Furthermore, Matoba et al (14) and some Soviet authors (5) have reported that the vibration syndrome involves the central nervous system. This involvement has been hotly debated, special reference being given to autonomic nervous disorders, but it has not yet achieved general acceptance (6).

With respect to the effects of local vibration on the autonomic nervous system, the findings of Pyykkö et al (17) are very interesting. The present study has not only obtained similar results, but also findings indicating that there is also an association between VWF and hearing loss at frequencies they did not examine and that there is also a relationship between hearing loss and fingertip skin temperature. Kurumatani et al (13) demonstrated the validity of measuring skin temperature during the first $10 \mathrm{~min}$ after hand cooling in discriminating men with VWF from normal ones. Therefore we may conclude that the digital circulatory disturbance of the workers with vibration syndrome was associated with additional hearing threshold shift. The cause of this increased hearing damage is not known.

One possible cause of the association is an effect of the activated sympathetic nervous system as Pyykkö et al (17) assumed. An elevated sympathetic tone has been suggested for patients with vibration syndrome (15). One may speculate that a high sympathetic tone plays a part in the production of increased hearing damage, as unilateral sympathectomy in albino rats leads to less hearing loss on the operated side (3). Therefore, the extra hearing loss of the cases with digital circulatory disturbance in this study might have been caused by the influence of their higher sympathetic tone.

Another possible mechanism is suggested by studies on systemic arteritis, polyarteritis nodosa $(2,16)$. The patients with this disease often have secondary Raynaud's phenomenon, and some of them develop sensorineural hearing loss. As a possible mechanism to explain the hearing involvement, it has been proposed that thromboembolic events based on platelet hyperaggregability produces ischemic changes in the inner ear $(2,16)$. Increased platelet function has been found in the patients with VWF, and its possible relation to cerebrovascular diseases has been suggested (8). A hyperaggregability based on this increased platelet function might be enhanced by hyperviscosity of the whole blood in patients with vibration syndrome (1), and it might lead to ischemic hearing damage in men with VWF.
In our matched-pair case-referent study confounding due to age and operating hours for the tools was eliminated. But we could not control all the confounding variables. The case workers might have used the tools which produced more intense vibration and noise, or they might have operated the tools in a more hazardous manner than did the referents. Most lumberjacks in Japan have used several models of chain saws since the vibrating tools were introduced to forestry, and it was therefore difficult for this cross-sectional study to assess the vibration and noise levels of each tool having been used up to the present time. It was even more difficult to quantify the manner in which the tools were used by each subject.

Even though possible confounding due to vibration and noise level or the manner of tool use has remained unsolved, it is interesting that the present study and that of Pyykkö et al (17) have obtained similar results. To establish the association between VWF and hearing loss more clearly, further prospective studies allowing for such confounding are necessary.

\section{References}

1. Blunt RJ, Goerge AJ, Hurlow RA, Strachan CJL, Stuart J. Hyperviscosity and thrombotic changes in idiopathic and secondary Raynaud's phenomenon. Br J Haematol 45 (1980) $651-658$.

2. Bomholt A, Bjerre Knudsen J, Permin H, Tommerup $\mathrm{B}$, Gormsen J. Profound sensorineural hearing loss in polyarteritis nodosa. Arch Otorhinolaryngol 236 (1982) $53-58$.

3. Borg E. Protective value of sympathectomy of the ear in noise. Acta Physiol Scand 115 (1982) 281-282.

4. Chang CP. Cold water immersion test in patients with vibration disease. Jpn J Ind Health 18 (1976) 453—463.

5. Gemne G. "Vibration disease"' as a central nervous system disorder - Development, symptomatology and pathophysiology of Soviet and Japanese classification. In: Gemne G, Taylor W, ed. Hand-arm vibration and the central autonomic nervous system. Multi-science Publishing, London 1983, pp 19-35.

6. Gemne G, Taylor W. Editor's foreword. In: Gemne G, Taylor $\mathrm{W}$, ed. Hand-arm vibration and the central autonomic nervous system. Multi-Science Publishing, London 1983, pp XI.

7. Holmgren G, Johnsson L, Kylin B, Linde O. Noise and hearing of a population of forest workers. In: Robinson DW, ed. Occupational hearing loss. Academic Press, London 1971, pp 35-42.

8. Ikehata K, Kawauchi S, Kohno F, Nishiyama M, Ide $\mathrm{N}$. Increased platelet function and Von Willebrand factor in vibration syndrome. Tokushima J Exp Med 27 (1980) $23-28$.

9. Iki M, Kurumatani N. Moriyama T. A field study on noise-induced hearing loss in the forest workers. In: See LC, Fook LW, Peng LH, Nam OC, ed. Proceedings of 10th Asian conference on occupational health, Singapore 5-10 Sept, 1982, pp 369-375.

10. Iki M, Kurumatani N, Moriyama T. Vibration-induced white fingers and hearing loss. Lancet 2 (1983) 282--283.

11. International Organization for Standardization. Acoustics - Standard reference zero for the calibration of pure-tone audiometers. Geneva 1975. (ISO 389).

12. Japanese Industrial Standard. Diagnostic audiometers. Tokyo 1963. (JIS T 1201-1963).

13. Kurumatani N, Iki M, Hirata K, Moriyama T, Satoh 
M, Arai T. Usefulness of fingertip skin temperature for examining peripheral circulatory disturbances of vibrating tool operators. Scand J Work Environ Health 12 (1986) 245-248.

14. Matoba $\mathrm{T}$, Kusumoto $\mathrm{H}$, Omura $\mathrm{H}$, Kotorii $\mathrm{T}$, Kuwahara $\mathrm{H}$, Takamatsu M. Digital plethysmographic responses to auditory stimuli in the patients with vibration disease. Tohoku J Exp Med 115 (1975) 385-392.

15. Matoba $\mathrm{T}$, Mizobuchi $\mathrm{H}$, Ito $\mathrm{T}$, Chiba M, Toshima $\mathrm{H}$. Further observations of the digital plethysmography and its clinical applications. Angiology 32 (1981) 62-72.

16. McNeil NF, Berke M, Reingold IM. Polyarteritis nodosa causing deafness in an adult: Report of a case with special reference to concepts about the disease. Ann Int Med 37 (1952) 1253-1267.
17. Pyykkö I, Starck J, Färkkilä M, Hoikkala M, Korhonen $O$, Nurminen $M$. Hand-arm vibration in the aetiology of hearing loss in lumberjacks. Br J Ind Med 38 (1981) $281-289$.

18. Taylor W, Permear PL, Pearson J. Raynaud's phenomenon in forestry chain saw operators. In: Taylor W, ed. The vibration syndrome. Academic Press, London 1974, pp 121-139.

19. Taylor W, Brammer AJ. An introduction and review. In: Brammer AJ, Taylor W, ed. Vibration effects on the hand and arm in industry. John Wiley \& Sons, London 1982, pp 1-12.

20. Yokouchi K. Studies on the physiological hearing loss by age [in Japanese]. J Otolaryngol Jpn 67 (1964) 1307-1319. (English abstract). 